\title{
Invited review: Determination of large-scale individual dry matter intake phenotypes in dairy cattle
}

\author{
D. J. Seymour, ${ }^{1,2}$ A. Cánovas, ${ }^{2}$ C. F. Baes, ${ }^{2,3}$ T. C. S. Chud, ${ }^{2}$ V. R. Osborne, ${ }^{1}$ J. P. Cant, ${ }^{1}$ L. F. Brito, ${ }^{4}$ \\ B. Gredler-GrandI, ${ }^{5}$ R. Finocchiaro, ${ }^{6}$ R. F. Veerkamp, ${ }^{5}$ Y. de Haas, ${ }^{5}$ and F. Miglior ${ }^{2 *}$ \\ ${ }_{1}^{1}$ Centre for Nutrition Modelling, Department of Animal Biosciences, University of Guelph, N1G 2W1, Guelph, Ontario, Canada \\ ${ }^{2}$ Centre for Genetic Improvement of Livestock, Department of Animal Biosciences, University of Guelph, N1G 2W1, Guelph, Ontario, Canada \\ ${ }^{3}$ Institute of Genetics, Vetsuisse Faculty, University of Bern, 3001, Bern, Switzerland \\ ${ }^{4}$ Department of Animal Sciences, Purdue University, West Lafayette, IN 47907 \\ ${ }^{5}$ Animal Breeding and Genomics, Wageningen University and Research, $6700 \mathrm{AH}$ Wageningen, the Netherlands \\ ${ }^{6}$ Associazione Nazionale Allevatori delle Razze Frisona e Jersey Italiana, 26100 Cremona, Italy
}

\section{ABSTRACT}

Feed efficiency has been widely studied in many areas of dairy science and is currently seeing renewed interest in the field of breeding and genetics. A critical part of determining how efficiently an animal utilizes feed is accurately measuring individual dry matter (DM) intake. Currently, multiple methods are used to measure feed intake or determine the DM content of that feed, resulting in different levels of accuracy of measurement. Furthermore, the scale at which data need to be collected for use in genetic analyses makes some methodologies impractical. This systematic review aims to provide an overview of the current methodologies used to measure both feed intake in ruminants and DM content of feedstuffs, current methods to predict individual DM intake, and applications of large-scale intake measurements. Overall, advances in milk spectral data analysis present a promising method of estimating individual DM intake on a herd scale with further validation of prediction models. Although measurements of individual feed intake rely on the same underlying principle, the methods selected are largely dictated by the costs of capital, labor, and necessary analyses. Finally, DM methodologies were synthesized into a comprehensive protocol for use in a variety of feedstuffs.

Key words: dry matter intake, feed efficiency

\section{INTRODUCTION}

The large economic impact of feeding costs in dairy cattle production has motivated the investigation of the genetic background of feed intake and efficiency of nutrient utilization, which were shown to be mod-

Received February 8, 2019

Accepted April 30, 2019.

*Corresponding author: fmiglior@uoguelph.ca erately heritable traits (e.g., Korver, 1988; Veerkamp, 1998; Pryce et al., 2014). However, genetic selection for improved feed efficiency has been rather limited, especially due to the costs and practical limitations of individually measuring feed intake for a large number of animals. Dry matter intake is a key variable in assessing feed efficiency, which is obtained based on 2 steps: the measurement of feed intake and the estimation of DM content of that feed. Proper management of DMI is critical because insufficient intake represents a major limitation of milk synthesis (Allen, 2000). In production settings, proper management can be accomplished by visually assessing the amount of feed refused (i.e., orts) in a given period and adjusting the amount offered as necessary (Bolsen and Pollard, 2004). However, in the context of research and for selective breeding based on the genetic merit of feed efficiency, quantitative measures of DMI on individual animals are needed in addition to information on ration composition. Although DMI can be easily measured in studies using small groups of animals, the traditional method of weighing orts is not economically feasible for population-scale analysis.

Currently, the lack of large-scale DMI data collection is a limiting factor for the implementation of genetic and genomic selection for improved feed efficiency, where a large number of measurements (hundreds to thousands of animals) is typically required for accurate estimation of genetic parameters and breeding values. Dry matter intake is of particular importance in the development of novel breeding objectives, such as those regarding feed efficiency and methane emissions (e.g., Korver, 1988; de Haas et al., 2011; Pryce et al., 2014; Miglior et al., 2017). In addition to challenges associated with measuring feed intakes, no single standard has been adopted to estimate DM content of feeds. This variability in methodology will translate to variation in results across studies (e.g., Ahn et al., 2014) and result 
in subsequent difficulty in comparing study results. In an effort to address these issues, this review aims to (1) highlight current methods of measuring and predicting DMI in dairy cattle and (2) systematically review methods currently used to measure DMI and critically assess their application to large populations.

\section{PHENOTYPIC DMI PREDICTION MODELS}

\section{Ration Formulation}

Dry matter intake is the backbone of ration formulation because it sets the limit for nutrient intake. Although individual companies, governments, and other organizations may develop their own ration formulation models and guidelines [e.g., INRA feeding system for ruminants (INRA, 2018), NorFor (Volden, 2011)], 2 models featured prominently in the dairy nutrition literature are the NRC (NRC, 2001) and Cornell Net Carbohydrate and Protein System (CNCPS; Tylutki et al., 2008) models. Although it is best practice to use observed DMI values when formulating rations with any model, both NRC and CNCPS include prediction equations for DMI for cattle at different life stages (e.g., calves, growing heifers, mature cows) and different stages of lactation. The CNCPS model predicts DMI for lactating dairy cows based on BW, FCM yield, ambient temperature, and lot mud depth (which negatively affects an animal's willingness to go to the feed bunk; Fox et al., 2004), whereas the NRC model uses metabolic BW (BW ${ }^{0.75}$; Kleiber, 1961), FCM, and week of lactation (to account for low DMI in early lactation; NRC, 2001). In ration formulation, it is common practice to use herd averages for the input variables described above. Although estimation of DMI for individual animals is possible, the use of conventional ration formulation software to estimate individual intakes for an entire herd would be neither economically nor practically feasible in large herds at this time. With the advancements in on-farm data collection and the dearth of information available on individual animals, it is very likely that ration formulation for individual animals will become feasible in the near future; however, until the technology to mix and feed specific rations to individual animals becomes practical, this does not serve to benefit the average producer.

\section{Residual Feed Intake and Linear Regression Models}

Whereas the models used in ration formulation are deterministic, the models used to calculate residual feed intake (RFI) are stochastic in nature. The concept of RFI was first described by Koch et al. (1963) in beef cattle as a measure of feed efficiency. It has since been applied to many other agricultural species, though it has grown popular in dairy cattle only in recent years (Waghorn et al., 2012). To calculate RFI, DMI is regressed on the various energy sinks of the animal; in dairy cattle, this can include parameters representative of milk yield (i.e., FCM, fat- and protein-corrected milk yield, or ECM yield), metabolic BW, BW change, and week of lactation (Byskov et al., 2017). As with all statistical analyses, it is important to use sound practices when constructing statistical models and interpreting effects. For instance, including an effect for time captures variation that may arise from sources that were not measured. Furthermore, the terms included in the model will depend on the data available and the hypothesis being tested. It is a common misconception that the objective is to directly predict RFI. On the contrary, RFI is the residual term of the DMI prediction model - that is, the difference between the observed DMI and that expected based on contemporary group performance and the energy sinks included in the model (Veerkamp et al., 1995). One of the major shortcomings of RFI is that because it is the residual error of the DMI prediction model, any residual variance due to an improperly specified statistical model or errors in measurement is included in the measurement and may account for 41 to $47 \%$ of the variation in RFI (Fischer et al., 2018b). It is also important to note that RFI in the traditional sense does not adequately account for differences in ration composition, making it difficult to compare between contemporary groups. A more robust method is to correct for the net energy content of the ration, termed residual net energy intake (Fischer et al., 2018a), while accounting for differences between contemporary groups (e.g., housing and management conditions).

\section{Milk MIR Spectral Data}

As early as 2011, milk mid-infrared (MIR) spectral data have been used to estimate energy balance in dairy cattle (e.g., McParland et al., 2011, 2012). Subsequently, the same methodology was applied to the prediction of RFI (McParland et al., 2014); however, as previously described, observed DMI values are required for the calculation of RFI. In an effort to eliminate the need for individual DMI recording, Shetty et al. (2017) used a partial least squares approach to develop models to estimate DMI based on MIR spectral data. These models were further improved by Dórea et al. (2018) using an artificial neural network approach. Further work needs to be done in terms of validation (Dórea et al., 2018); however, these models represent a promising means of estimating individual energy intake, as MIR is widely used to determine composition in milk testing 
(McParland et al., 2011; Wallén et al., 2018), which would eliminate the need for additional infrastructure. As energy intake can be described mathematically as the product of DMI and diet energy density, the estimation of DMI from energy intake is straightforward.

\section{Spatial Imaging}

Methods of determining individual feed intakes are currently being developed that make use of advanced image processing technology to assess feed intake, such as the machine vision method of Shelley et al. (2016) and the photogrammetry method developed by Bloch et al. (2019). Recently, Viking Genetics (Randers, Denmark) demonstrated the use of a consumer 3D camera system that is capable of both identifying individual cows in a herd and measuring individual feed intakes (Lassen et al., 2018; Thomasen et al., 2018). Although these systems have yet to be extensively tested, it is possible that implementation on a large scale could generate data similar to feed bunk systems at a reduced capital cost.

\section{APPLICATIONS OF LARGE-SCALE INDIVIDUAL DMI MEASUREMENTS}

Being able to collect DMI data on individual animals throughout a herd would provide benefits in both production and research settings. Dairy producers around the world have demonstrated an interest in a variety of high-throughput technologies that help improve the management of large herds, particularly with the shift from tiestall to freestall housing (Gargiulo et al., 2018). The ability to integrate DMI measurements with other data produced on-farm, such as milk and component yields, BW, and BCS, would allow producers to make the shift from feeding animals as groups to feeding animals to their specific requirements as dictated by their individual production level. Furthermore, knowledge of feed intake would enable the estimation of energy balance throughout lactation and bolster the current methods of detection of various metabolic disorders, such as subclinical ketosis.

Dry matter intake has always been a staple measurement in dairy nutrition research, but it is now gaining popularity in the field of breeding and genetic selection. With the current interest in traits such as feed efficiency and methane emissions (e.g., Pryce et al., 2014; Miglior et al., 2017), a far greater number of both animals and records is needed to elucidate the genetic variance and markers associated with these phenotypes. It would take several years for a single research group to generate the volume of data necessary to perform these analyses, which has spurred the formation of a variety of global research partnerships [e.g., those based out of the United States (VandeHaar et al., 2016), Scandinavia (Li et al., 2016), and Australasia (Pryce et al., 2018)], the Global Dry Matter Initiative (Berry et al., 2014), Genomic Management Tools to Optimize Resilience and Efficiency (https://www.gentore.eu), and the Efficient Dairy Genome Project (https://genomedairy .ualberta.ca). By pooling data and expertise, these groups are able to generate vast amounts of data from which the biological underpinnings of feed efficiency can be characterized, which can then be used to incorporate the trait into breeding programs (Lu et al., 2018).

\section{SYSTEMATIC REVIEW OF CURRENT PRACTICES}

A systematic review of the recent literature was conducted to identify techniques currently used in research settings to determine both as-fed intakes and feed DM content. An initial set of 568 articles published between August 2017 and August 2018 was retrieved from the journals listed in Table 1. Articles were then screened for the following exclusion criteria: meta-analyses or reviews; nonruminant species; no description of DM estimation methodology or determination of as-fed intakes; methodology presented in a separate publication; liquid diet (i.e., milk or milk replacer); and in situ, ex vivo, or in vitro studies. Exclusion of publications based on these criteria resulted in a final working list of 266 publications. From these publications, a database was created containing the number of animals used per study, the species of ruminant (e.g., dairy or beef cattle, sheep, goat), method used to measure feed intake, and method used to determine feed DM content. A descriptive summary of this database is presented in Table 2 . Although many different methodologies measure both feed intake and DM content, only those used in the data set are presented in this review in an effort to reflect current practices.

\section{Determination of As-Fed Intakes}

Although studies used different technologies and methods to measure feed intake, the underlying principle - determining how much feed was offered and how much feed was refused by the animal-remained the same. By far, the most commonly used methodology was the weighing of orts ( $70 \%$ of studies reviewed). Although this technique is simple and inexpensive when only a small number of animals are tested, it is labor intensive. Furthermore, this technique works well in a tiestall setting, where separate feed bunks can be allocated to each animal, but fails when animals are group housed with access to a communal bunk, where only a group average can be determined effectively (e.g., Silva 
Table 1. Selection criteria for the initial pool of articles reporting techniques currently used in research settings to determine both as-fed intakes and feed DM content

\begin{tabular}{lll}
\hline Journal & Issues included & Sections \\
\hline Journal of Dairy Science & $100(8)$ to $101(8)$ & Animal nutrition \\
Journal of Animal Science & $95(8)$ to $96(7)$ & Forage-based livestock systems, ruminant nutrition \\
Journal of Dairy Research & $84(3)$ to $85(2)$ & Research articles \\
Animal & $11(8)$ to $12(8)$ & Nutrition \\
Animal Feed Science and Technology & 230 to 241 & Ruminants \\
\hline
\end{tabular}

et al., 2018). Semiquantitative methods, such as the South Dakota State 4-point bunk scoring system (Bolsen and Pollard, 2004; Antonelo et al., 2017), can be used to roughly estimate feed intakes, although these are more suitable for management than for research or genetic selection.

After weighing orts, the majority of other methodologies addressed the issue of determining individual feed intakes in group-housing settings. These technologies included the Calan Broadbent Feeding System (i.e., Calan gates; American Calan Inc., Northwood, NH), the Controlling and Recording Feed Intake system (i.e.,

Table 2. Summary of publications included in review

\begin{tabular}{ll}
\hline Field & Summary \\
\hline Sample size $^{1}$ & $51(2-365)$ \\
Species $^{2}$ & Dairy cattle (144) \\
& Beef cattle (66) \\
& Sheep (40) \\
& Goats (13) \\
& Multiple species (2) \\
& Orts (185) \\
& Not specified (17) \\
& Calan gate (15) \\
& Insentec feeder (12) \\
& Rising plate meter/regression (12) \\
& GrowSafe feeder (8) \\
& Other feeders (8) \\
& Indigestible markers (5) \\
& Other methodology ${ }^{5}(136)$ \\
& AOAC (82) \\
& Not specified (29) \\
& External laboratory (10) \\
& ISO (4) \\
& VDLUFA (3) \\
& MAFF (2) \\
\hline
\end{tabular}

\footnotetext{
${ }^{1}$ Presented as average sample size (range).

${ }^{2}$ Number of studies presented in brackets.

${ }^{3}$ Calan gate: American Calan Inc. (Northwood, NH); Insentec feeder: Hokofarm Group BV (Marknesse, the Netherlands); GrowSafe feeder: Growsafe (Calgary, AB, Canada).

${ }^{4} \mathrm{AOAC}=$ Association of Official Analytical Chemists (Gaithersburg, MD); ISO = International Organization for Standardization (Geneva, Switzerland); VDLUFA = Association of German Agricultural Analytic and Research Institutes (Darmstadt, Germany); MAFF = UK Ministry of Agriculture, Fisheries and Food (London, UK).

${ }^{5}$ Methods with no citation for drying temperatures and times used that did not align with other standard methodologies.
}

CRFI; BioControl Norway As, Rakkestad, Norway), the GrowSafe System (Growsafe, Calgary, AB, Canada), and the roughage intake control system (i.e., Insentec feeders; Hokofarm Group BV, Marknesse, the Netherlands). These systems use animal radio frequency identification tags either to restrict feed bunk access to a specific animal (e.g., Calan gates) or to electronically record when a given animal enters the feed bunk and the difference in weight of feed upon exiting the bunk (e.g., GrowSafe, CRFI, and Insentec). Access to both CRFI and Insentec feed bunks can also be restricted to specific animals. Although these systems may constitute a significant investment in infrastructure, this is offset by the reduction of labor costs associated with weighing orts (except when using Calan gates, which require manual weighing of orts) while allowing for the measurement of individual feed intakes on a much larger number of animals.

For studies that were performed in a pasture-based system, herbage intake was estimated either by linear regression or using indigestible fecal markers. The majority of these studies used linear regressions to estimate the average herbage mass consumed per animal. To accomplish this, a rising plate meter is used to measure the herbage height in representative quadrats. The quadrats are then harvested and analyzed for DM content. The data are then used to develop a linear regression predicting DM yield per unit area from rising plate meter height (e.g., Steyn et al., 2018). By measuring herbage heights before and after the grazing period and taking account of stocking density, it is possible to estimate the average DMI per animal, though it is important to note that this method has very low accuracy for individual intakes and is more suited for estimating the average intake for a group of animals.

Several other pasture-based studies made use of fecal excretion of indigestible markers, such as indigestible NDF (Marquez et al., 2017), chromic oxide and titanium dioxide (van Wyngaard et al., 2018), fecal CP, or plant wax markers, such as n-alkanes (Savian et al., 2018). Although these methods yield individual and more accurate DMI data compared with herbage mass prediction equations, labor costs are drastically higher 
due to dosing animals with each marker, performing individual fecal collections, and analyzing samples for the respective markers. Furthermore, knowledge of total fecal excretion per individual animal is required to accurately estimate DMI using the fecal CP method, which presents a significant challenge in most pasturebased systems (Savian et al., 2018).

\section{Determination of DM Content}

When determining DM content of feedstuffs, a variety of procedures were implemented. Roughly half of the articles reviewed (136 of 266) described their methods directly in the text (including whether samples were sent to an external laboratory), 91 referenced a published standard methodology, 10 referenced a previous publication, and the remaining 29 provided no detail on DM analyses.

An outline of the standard methodologies referenced is presented in Table 3. Of the 91 papers that referenced a standard method, 82 were published in Official Methods of Analysis (AOAC International, 2005). The remaining publications referenced either International Organization for Standardization (Geneva, Switzerland) procedure 1999:6496 (ISO, 1999) or publications by either the Association of German Agricultural Analytic and Research Institutes (VDLUFA, 2007) or the United Kingdom Ministry of Agriculture, Fisheries and Food (MAFF, 1981). Several publications stated that DM analyses were conducted by external laboratories, the most common in the United States being Dairy One (Ithaca, NY). As such, Dairy One and 2 other feed labs (A\&L Canada Laboratories, London, ON, Canada; SGS AgriFood Labs, Guelph, ON, Canada) were contacted to determine the methods used for routine DM analysis at each location; these are presented in Table 3.

After a thorough review of the methodologies presented in the literature without citation of a formal standard, the majority were variations of procedures adopted by the National Forage Testing Association (NFTA, 1993). These procedures provide a thorough overview of the various methods of determining DM as applied to animal feeds and forages, with particular respect to feedstuffs with high VFA content, such as silages. A brief summary of these procedures is provided below as they relate to in-house DM determination, with a particular focus on oven-drying methods. Although procedures have been developed to determine DM content using microwaves and hand-held nearinfrared reflectance spectrometers, the results from microwave drying are highly variable, and insufficient research has been conducted using hand-held nearinfrared reflectance devices (Johnston, 2018).
Partial Versus Analytical DM. Partial DM is achieved by drying samples $\leq 60^{\circ} \mathrm{C}$, resulting in a sample with low moisture content (3-15\%). This allows for adequate grinding of samples for further analyses and is used in NFTA 2-step DM methods (NFTA, 1993). Analytical or laboratory DM represents the true DM content of a feedstuff and is best determined using the Karl Fischer titration method (AOAC International, 2005, method 2001.12), which is considered the reference for all DM methods (Thiex and Richardson, 2003).

Single-Step Methods. For feedstuffs with a DM content $>85 \%$, oven drying for $2 \mathrm{~h}$ at $135^{\circ} \mathrm{C}$ provides an estimate of DM that closely agrees with the Karl Fischer method and is highly repeatable (NFTA, 1993, method 2.1.1; AOAC International, 2005, method 930.15). Oven drying at $100^{\circ} \mathrm{C}$ for $24 \mathrm{~h}$ (AOAC International, 2005, method 967.03 ) or $105^{\circ} \mathrm{C}$ for $16 \mathrm{~h}$ (NFTA, 1993, method 2.1.2) are also suitable methods for single-step DM determination, though such methods limit the downstream uses of the sample. All single-step methods are inappropriate for use with fermented samples due to VFA and alcohol losses (NFTA, 1993).

2-Step Methods. For samples with an initial DM content of $<85 \%$, it is recommended to use 2-step methods (NFTA, 1993, method 2.2.3) to facilitate adequate homogenization of samples. In the first step, the partial $\mathrm{DM}$ is determined by drying samples at $55^{\circ} \mathrm{C}$ for 16 to $24 \mathrm{~h}$ (NFTA, 1993, method 2.2.1.1), which approximates the DM determined by toluene distillation (AOAC International, 2005, method 925.04) for silages. After partially drying, samples can be ground to pass through a 1- to 2-mm screen (AOAC International, 2005, method 950.02) and further dried using one of the single-step methods previously described to determine the analytical DM. The total DM content of the samples is calculated as the product of the partial and analytical DM.

\section{RECOMMENDATIONS FOR THE DETERMINATION OF DM CONTENT}

Based on the different methodologies reviewed herein, we have provided the following recommended methodology for the determination of DM content. These procedures may have to be adjusted based on study design, ration formulation, method of feed delivery (e.g., TMR, component feeding), and other factors. The following method is suitable for the estimation of DM of all feed types, though it may affect other downstream analyses using the same sample. The use of this methodology should provide results comparable with those of the Karl Fischer titration method (AOAC International, 2005, method 2001.12) while reducing variability in results across studies (Ahn et al., 2014). 
SEYMOUR ET AL.

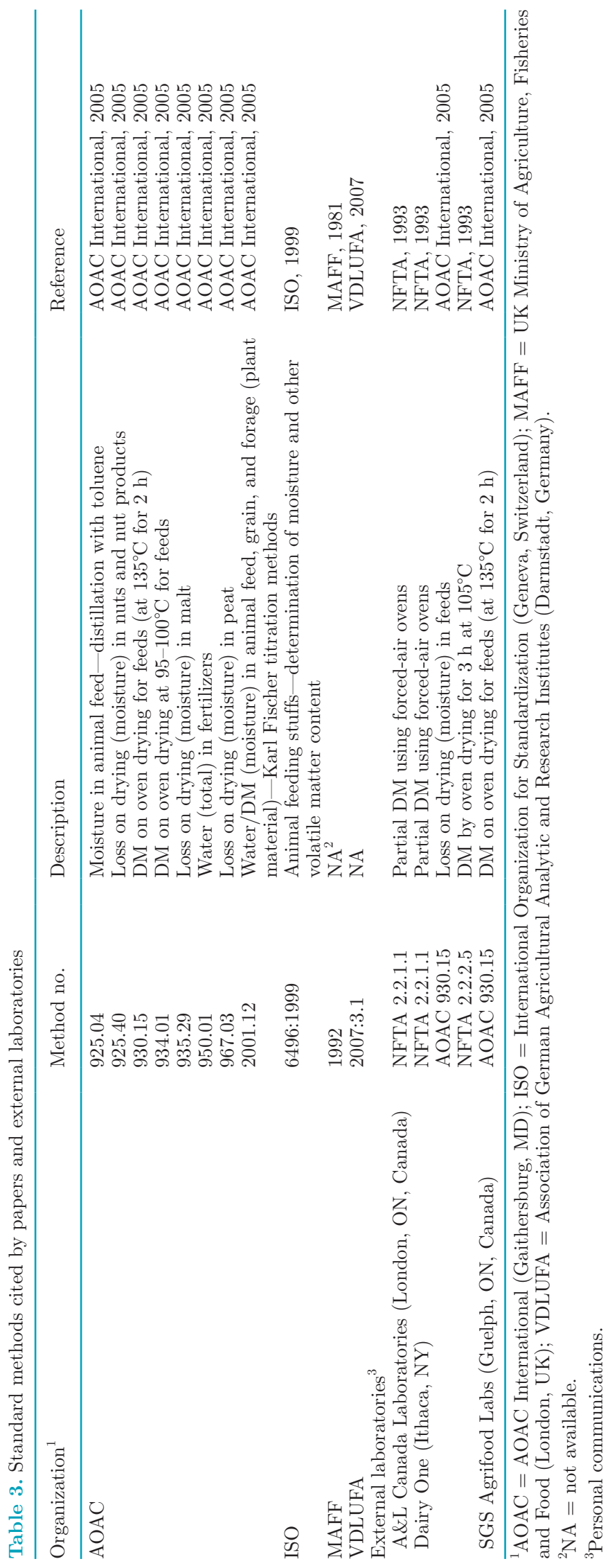




\section{Sample Collection}

Representative samples of rations, feedstuffs, or both should be collected weekly at minimum, whereas samples of orts should be collected daily from each feed bunk and pooled by week (depending on study goals and length of trial). In the instance where feedstuffs are of heterogeneous particle size or not mixed thoroughly (e.g., component feeding), researchers should be wary of the effect of sorting behavior on both composition of feed consumed by the animal and subsequent DM analyses (Sova et al., 2013) and adjust sample collection accordingly. It is important to include orts in DM analyses because additional moisture is added to orts in the form of saliva, spilled water, and other fluids, which will cause differences in the DM relative to the ration that was offered. Regarding collecting samples from pasture, the nutrient profile of plants has been shown to change over the course of the daily photoperiod (Brito et al., 2008); this should be taken into account in the collection of sufficiently representative samples. Samples should be stored in airtight containers at $-20^{\circ} \mathrm{C}$ until analyzed for DM.

\section{Determination of Partial DM}

To determine partial DM, prepare sufficient empty, oven-safe containers to analyze duplicates of feed and orts samples by drying at $55^{\circ} \mathrm{C}$ for $2 \mathrm{~h}$. Using a gravimetric balance, weigh containers to the nearest $0.01 \mathrm{~g}\left(\mathrm{~W}_{1}\right)$. Tare the empty container and weigh approximately $150 \mathrm{~g}$ of sample into the container and record weight to the nearest $0.01 \mathrm{~g}\left(\mathrm{~W}_{2}\right)$. Ensure that samples are spread evenly throughout the container. Dry samples in a forced-air drying oven at $55^{\circ} \mathrm{C}$ for 24 $\mathrm{h}$, leaving adequate space between containers to allow air to circulate. Remove containers from the oven and allow to equilibrate at room temperature for $4 \mathrm{~h}$. Weigh the sample and container, recording the weight to the nearest $0.01 \mathrm{~g}\left(\mathrm{~W}_{3}\right)$. The partial DM $\left(\mathrm{DM}_{\mathrm{P}}\right.$; percentage basis) is calculated as

$$
\mathrm{DM}_{\mathrm{P}}(\%)=\left(\mathrm{W}_{3}-\mathrm{W}_{1}\right) / \mathrm{W}_{2} \text {. }
$$

\section{Determination of Analytical DM}

To determine analytical DM, grind samples to pass through a $1-\mathrm{mm}$ screen. Preheat containers and 3 porcelain crucibles by placing in an oven at $100^{\circ} \mathrm{C}$ for 2 $\mathrm{h}$. Warm gravimetric balance by placing each crucible sequentially on the balance for $20 \mathrm{~s}$ each. One at a time, remove containers from the oven, place on the balance for $15 \mathrm{~s}$, and record weight $\left(\mathrm{W}_{4}\right)$ to the nearest
$0.1 \mathrm{mg}$. After weighing, allow containers and balance to cool for $1 \mathrm{~h}$. Weigh approximately $2 \mathrm{~g}$ of sample into each container and record the weight of the sample and container to the nearest $0.1 \mathrm{mg}\left(\mathrm{W}_{5}\right)$. Shake the container to evenly distribute the sample. Place containers, in addition to 3 porcelain crucibles, into an oven preheated to $100^{\circ} \mathrm{C}$ and dry uncovered for $24 \mathrm{~h}$. Warm gravimetric balance and weigh samples to nearest 0.1 $\mathrm{mg}\left(\mathrm{W}_{6}\right)$ as previously described. The analytical DM $\left(\mathrm{DM}_{\mathrm{A}}\right.$; percentage basis $)$ is calculated as

$$
\mathrm{DM}_{\mathrm{A}}(\%)=\left(\mathrm{W}_{6}-\mathrm{W}_{4}\right) /\left(\mathrm{W}_{5}-\mathrm{W}_{4}\right) .
$$

\section{Calculation of DMI}

As previously discussed, as-fed intakes are calculated as the difference between the amount of feed offered and the amount of feed refused. The determination of these values will depend on the method of feed delivery; however, the underlying principle is the same. The total DM ( $\mathrm{DM}_{\mathrm{T}}$; percentage basis) is the product of the partial and analytical DM:

$$
\mathrm{DM}_{\mathrm{T}}(\%)=\mathrm{DM}_{\mathrm{P}}(\%) \times \mathrm{DM}_{\mathrm{A}}(\%) .
$$

This calculation will produce the weekly average total DM of both feed and orts samples. Dry matter intake is then calculated as the difference in weights (W) of feed offered and orts multiplied by their respective total DM:

$$
\mathrm{DMI}=\left(\mathrm{W}_{\text {Feed }} \times \mathrm{DM}_{\mathrm{T}, \text { Feed }}\right)-\left(\mathrm{W}_{\text {Orts }} \times \mathrm{DM}_{\mathrm{T}, \mathrm{Orts}}\right) .
$$

When performing these calculations, it is important to ensure that observations are multiplied by the correct total DM based on sampling week. Additionally, ensuring that orts are matched to the correct animal is imperative for determining individual intakes. In situations where animals have access to multiple feed bunks, it may be more appropriate to use an average total DM for orts across all feed bunks.

\section{CONCLUSIONS}

When determining DMI on a herd scale, the underlying principle is the same regardless of the technology used. The main limitation of measuring DMI on the herd scale is the measurement of individual feed intakes, particularly in group-housing systems. To address this limitation, research groups and herd managers will have to evaluate the trade-off of labor for capital investment to determine which feed delivery system best meets 
their specific needs. Once the issue of individual intakes is addressed, the use of a standard method of determining DM content will help ensure that phenotypic measurements are consistent across populations. With adequate validation, milk MIR spectral data present a convenient method of generating phenotypes for a large number of animals using existing infrastructure and practices.

\section{ACKNOWLEDGMENTS}

We gratefully acknowledge funding by the Efficient Dairy Genome Project, funded by Genome Canada (Ottawa, ON, Canada), Genome Alberta (Calgary, AB, Canada), Ontario Genomics (Toronto, ON, Canada), Alberta Ministry of Agriculture (Edmonton, AB, Canada), Ontario Ministry of Research and Innovation (Toronto, ON, Canada), Ontario Ministry of Agriculture, Food and Rural Affairs (Guelph, ON, Canada), Canadian Dairy Network (Guelph, ON, Canada), GrowSafe Systems (Airdrie, AB, Canada), Alberta Milk (Edmonton, AB, Canada), Victoria Agriculture (Melbourne, Australia), Scotland's Rural College (Edinburgh, UK), USDA Agricultural Research Service (Beltsville, MD), Qualitas AG (Zug, Switzerland), and Aarhus University (Aarhus, Denmark).

\section{REFERENCES}

Ahn, J. Y., D. Y. Kil, C. Kong, and B. G. Kim. 2014. Comparison of oven-drying methods for determination of moisture content in feed ingredients. Asian-australas. J. Anim. Sci. 27:1615-1622.

Allen, M. S. 2000. Effects of diet on short-term regulation of feed intake by lactating dairy cattle. J. Dairy Sci. 83:1598-1624.

Antonelo, D. S., N. A. Lancaster, S. Melnichenko, C. R. Muegge, and J. P. Schoonmaker. 2017. Effects of clay on toxin binding capacity ruminal fermentation, diet digestibility, and growth of steers fed high-concentrate diets. J. Anim. Sci. 95:4658-4667.

AOAC International. 2005. Official Methods of Analysis. AOAC International, Gaithersburg, MD. http://www.eoma.aoac.org.

Berry, D. P., M. P. Coffey, J. E. Pryce, Y. de Haas, P. Lovendahl, N Krattenmacher, J. J. Crowley, Z. Wang, D. Spurlock, K. Weigel, K. Macdonald, and R. F. Veerkamp. 2014. International genetic evaluations for feed intake in dairy cattle through the collation of data from multiple sources. J. Dairy Sci. 97:3894-3905.

Bloch, V., H. Levit, and I. Halachmi. 2019. Assessing the potential of photogrammetry to monitor feed intake of dairy cows. J. Dairy Res. 86:34-39.

Bolsen, K. K., and G. V. Pollard. 2004. Feed bunk management to maximize feed intake. Pages 227-238 in Proc. Western Canadian Dairy Seminar, Red Deer, AB, Canada. WCDS, Edmonton, AB, Canada.

Brito, A. F., G. F. Tremblay, A. Bertrand, Y. Castonguay, G. Bélanger, R. Michaud, H. Lapierre, C. Bencharr, H. V. Petit, D. R. Ouellett, and R. Berthiaume. 2008. Alfalfa cut at sundown and harvested as baleage improves milk yield of late-lactation dairy cows. J. Dairy Sci. 91:3968-3982.

Byskov, M. V., A. Fogh, and P. Lovendahl. 2017. Genetic parameters of rumination time and feed efficiency traits in primiparous Holstein cows under research and commercial conditions. J. Dairy Sci. 100:9635-9642. de Haas, Y., J. J. Windig, M. P. Calus, J. Dijkstra, M. Haan, A. Bannink, and R. F. Veerkamp. 2011. Genetic parameters for predicted methane production and potential for reducing enteric emissions through genomic selection. J. Dairy Sci. 94:6122-6134.

Dórea, J. R. R., G. J. M. Rosa, K. A. Weld, and L. E. Armentano. 2018. Mining data from milk infrared spectroscopy to improve feed intake predictions in lactating dairy cows. J. Dairy Sci. 101:58785889 .

Fischer, A., R. Delagarde, and P. Faverdin. 2018a. Identification of biological traits associated with differences in residual energy intake among lactating Holstein cows. J. Dairy Sci. 101:4193-4211.

Fischer, A., N. C. Friggens, D. P. Berry, and P. Faverdin. 2018b. Isolating the cow-specific part of residual energy intake in lactating dairy cows using random regressions. Animal 12:1396-1404.

Fox, D. G., L. O. Tedeschi, T. P. Tylutki, J. B. Russell, M. E. Van Amburgh, L. E. Chase, A. N. Pell, and T. R. Overton. 2004. The Cornell Net Carbohydrate and Protein System model for evaluating herd nutrition and nutrient excretion. Anim. Feed Sci. Technol. 112:29-78

Gargiulo, J. I., C. R. Eastwood, S. C. Garcia, and N. A. Lyons. 2018. Dairy farmers with larger herd sizes adopt more precision dairy technologies. J. Dairy Sci. 101:5466-5473.

INRA. 2018. INRA Feeding System for Ruminants. Wageningen Academic Publishers, Wageningen, the Netherlands.

ISO. (International Organization for Standardization). 1999. Animal feeding stuffs - Determination of moisture and other volatile matter content. 2nd ed. International Organization for Standardization, Geneva, Switzerland. https://www.iso.org/standard/12871 .html.

Johnston, C. E. 2018. Dry matter variability in corn and alfalfa silages fed to dairy cattle. MSc Thesis. Department of Animal Biosciences, University of Guelph, Guelph, ON, Canada.

Kleiber, M. 1961. The Fire of Life: An Introduction to Animal Energetics. Wiley Inc., New York, NY.

Koch, R. M., K. E. Gregory, D. Chambers, and L. A. Swiger. 1963 Efficiency of feed use in beef cattle. J. Anim. Sci. 22:486-494.

Korver, S. 1988. Genetic aspects of feed intake and feed efficiency in dairy cattle: A review. Livest. Prod. Sci. 20:1-13.

Lassen, J., J. R. Thomasen, R. H. Hansen, G. G. B. Nielsen, E. Olsen, P. R. B. Stentebjerg, N. W. Hansen, and S. Borchersen. 2018. Individual measures of feed intake on in-house commercial dairy cattle using 3D camera technology. Page 635 in Proc. World Congress on Genetics Applied to Livestock Production. Auckland, New Zealand. http://www.wcgalp.org.

Li, B., W. F. Fikse, J. Lassen, M. H. Lidauer, P. Lovendahl, P. Mantysaari, and B. Berglund. 2016. Genetic parameters for dry matter intake in primiparous Holstein, Nordic Red, and Jersey cows in the first half of lactation. J. Dairy Sci. 99:7232-7239.

Lu, Y., M. J. Vandehaar, D. M. Spurlock, K. A. Weigel, L. E. Armentano, E. E. Connor, M. Coffey, R. F. Veerkamp, Y. de Haas, C. R. Staples, Z. Wang, M. D. Hanigan, and R. J. Tempelman 2018. Genome-wide association analyses based on a multiple-trait approach for modeling feed efficiency. J. Dairy Sci. 101:3140-3154.

MAFF (Minstry of Agriculture, Fisheries and Food). 1981. The Analysis of Agricultural Materials: A Manual of the Analytical Methods Used by the Agricultural Development and Advisory Service/ Ministry of Agriculture, Fisheries and Food. 2nd ed. Her Majesty's Stationary Office, London, UK.

Marquez, D. C., M. F. Paulino, L. N. Renno, F. C. Villadiego, R M. Ortega, D. S. Moreno, L. S. Martins, D. M. de Almeida, M. P. Gionbelli, M. R. Manso, L. P. Melo, F. H. Moura, and M. S. Duarte. 2017. Supplementation of grazing beef cows during gestation as a strategy to improve skeletal muscle development of the offspring. Animal 11:2184-2192.

McParland, S., G. Banos, B. McCarthy, E. Lewis, M. P. Coffey, B. O'Neill, M. O'Donovan, E. Wall, and D. P. Berry. 2012. Validation of mid-infrared spectrometry in milk for predicting body energy status in Holstein-Friesian cows. J. Dairy Sci. 95:7225-7235.

McParland, S., G. Banos, E. Wall, M. P. Coffey, H. Soyeurt, R. F. Veerkamp, and D. P. Berry. 2011. The use of mid-infrared spec- 
trometry to predict body energy status of Holstein cows. J. Dairy Sci. 94:3651-3661.

McParland, S., E. Lewis, E. Kennedy, S. G. Moore, B. McCarthy, M. O'Donovan, S. T. Butler, J. E. Pryce, and D. P. Berry. 2014. Mid-infrared spectrometry of milk as a predictor of energy intake and efficiency in lactating dairy cows. J. Dairy Sci. 97:5863-5871.

Miglior, F., A. Fleming, F. Malchiodi, L. F. Brito, P. Martin, and C. F. Baes. 2017. A 100-year review: Identification and genetic selection of economically important traits in dairy cattle. J. Dairy Sci. 100:10251-10271.

NFTA (National Forage Testing Association). 1993. Forage Analyses Procedures. NFTA, Omaha, NE.

NRC. 2001. Nutrient Requirements of Dairy Cattle. 7th rev. ed. Natl. Acad. Sci., Washington, DC.

Pryce, J. E., T. T. T. Nguyen, M. Axford, G. Nieuwhof, and M. Shaffer. 2018. Symposium review: Building a better cow-The Australian experience and future perspectives. J. Dairy Sci. 101:3702-3713.

Pryce, J. E., W. J. Wales, Y. de Haas, R. F. Veerkamp, and B. J. Hayes. 2014. Genomic selection for feed efficiency in dairy cattle. Animal 8:1-10.

Savian, J. V., T. C. M. Genro, A. B. Neto, C. Bremm, E. B. Azevedo, D. B. David, H. L. Gonda, and P. C. F. Carvalho. 2018. Comparison of faecal crude protein and n-alkanes techniques to estimate herbage intake by grazing sheep. Anim. Feed Sci. Technol. 242:144-149.

Shelley, A. N., D. L. Lau, A. E. Stone, and J. M. Bewley. 2016. Short communication: Measuring feed volume and weight by machine vision. J. Dairy Sci. 99:386-391.

Shetty, N., P. Lovendahl, M. S. Lund, and A. J. Buitenhuis. 2017. Prediction and validation of residual feed intake and dry matter intake in Danish lactating dairy cows using mid-infrared spectroscopy of milk. J. Dairy Sci. 100:253-264.

Silva, L. G. T., R. F. Cooke, K. M. Schubach, A. P. Brandao, R. S. Marques, T. F. Schumaher, P. Moriel, and D. W. Bohnert. 2018. Supplementing a yeast-derived product to enhance productive and health responses of beef steers. Animal 12:1576-1583.

Sova, A. D., S. J. LeBlanc, B. W. McBride, and T. J. DeVries. 2013. Associations between herd-level feeding management practices, feed sorting, and milk production in freestall farms. J. Dairy Sci. 96:4759-4770.

Steyn, L., R. Meeske, and C. W. Cruywagen. 2018. The effect of replacing maize with dried apple pomace in the concentrate on performance of Jersey cows grazing kikuyu pasture. Anim. Feed Sci. Technol. 239:85-93.
Thiex, N., and C. R. Richardson. 2003. Challenges in measuring moisture content of feeds. J. Anim. Sci. 81:3255-3266.

Thomasen, J. R., J. Lassen, G. G. B. Nielsen, C. Borggard, P. R. B. Stentebjerg, R. H. Hansen, N. W. Hansen, and S. Borchersen. 2018. Individual cow identification in a commercial herd using 3D camera technology. Page 613 in Proc. World Congress on Genetics Applied to Livestock Production. Auckland, New Zealand. http:/ /www.wcgalp.org.

Tylutki, T. P., D. G. Fox, V. M. Durbal, L. O. Tedeschi, J. B. Russell, M. E. Van Amburgh, T. R. Overton, L. E. Chase, and A. N. Pell. 2008. Cornell Net Carbohydrate and Protein System: A model for precision feeding of dairy cattle. Anim. Feed Sci. Technol. 143:174-202.

van Wyngaard, J. D. V., R. Meeske, and L. J. Erasmus. 2018. Effect of concentrate feeding level on methane emissions, production performance and rumen fermentation of Jersey cows grazing ryegrass pasture during spring. Anim. Feed Sci. Technol. 241:121-132.

VandeHaar, M. J., L. E. Armentano, K. Weigel, D. M. Spurlock, R. J. Tempelman, and R. Veerkamp. 2016. Harnessing the genetics of the modern dairy cow to continue improvements in feed efficiency. J. Dairy Sci. 99:4941-4954.

VDLUFA (Association of German Agricultural Analytic and Research Institutes). 2007. Die chemische untersuchung von futtermitteln. Page 1 in Handbuch der landwirtschaftlichen versuchs-und untersuchungsmethodik (VDLUFA-Methodenbuch). Vol. III. VDLUFAVerlag, Darmstadt, Germany.

Veerkamp, R. F. 1998. Selection for economic efficiency of dairy cattle using information on live weight and feed intake: A review. J. Dairy Sci. 81:1109-1119.

Veerkamp, R. F., G. C. Emmans, A. R. Cromie, and G. Simm. 1995. Variance components for residual feed intake in dairy cows. Livest. Prod. Sci. 41:111-120.

Volden, H. 2011. NorFor-The Nordic feed evaluation system. EAAP Scientific Series. Wageningen Academic Publishers, Wageningen, the Netherlands.

Waghorn, G. C., K. A. Macdonald, Y. Williams, S. R. Davis, and R. J. Spelman. 2012. Measuring residual feed intake in dairy heifers fed an alfalfa (Medicago sativa) cube diet. J. Dairy Sci. 95:1462-1471.

Wallén, S. E., E. Prestlokken, T. H. E. Meuwissen, S. McParland, and D. P. Berry. 2018. Milk mid-infrared spectral data as a tool to predict feed intake in lactating Norwegian Red dairy cows. J. Dairy Sci. 101:6232-6243. 